\title{
Monitoring the laccase reaction of vanillin and poplar hydrolysate
}

\section{Valentin Sóti ${ }^{1}$, Nicolas Jacquet ${ }^{2}$, Sandra Apers ${ }^{3}$, Aurore Richel}

\author{
${ }^{2}$, Silvia Lenaerts ${ }^{4}$, Iris Cornet ${ }^{1}$ \\ ${ }^{1}$ BIT - Biochemical engineering technology - Faculty of Applied Engineering,
} University of Antwerp, Salesianenlaan 90, B-2660 Antwerp, Belgium

${ }^{2}$ Gembloux Agro-Bio Tech, Industrial Biological Chemistry, Gembloux Agro-Bio Tech, University of Liege, Passage des Déportés 2, B-5030 Gembloux, Belgium

${ }^{3}$ NatuRA (Natural product and Food - Research \& Analysis) - Faculty of Pharmaceutical, Biomedical and Veterinary Sciences, University of Antwerp, Universiteitsplein 1, B-2610 Antwerp, Belgium

${ }^{4}$ DuEL, Sustainable energy, air and water technology, Bioscience Engineering, University of Antwerp, Groenenborgerlaan 171, B-2020 Antwerp, Belgium

Correspondence to:

Iris Cornet

Valentin Soti

BIT - Biochemical engineering technology

Faculty of Applied Engineering, University of Antwerp

Salesianenlaan 30, B-2660 Hoboken, Belgium

iris.cornet@uantwerpen.be

valentin.soti@uantwerpen.be

This article has been accepted for publication and undergone full peer review but has not been through the copyediting, typesetting, pagination and proofreading process, which may lead to differences between this version and the Version of Record. Please cite this article as doi: $10.1002 /$ jctb.4789

This article is protected by copyright. All rights reserved. 


\begin{abstract}
BACKGROUND: Laccase is an intensively researched enzyme for industrial use. Except for decolorisation measurements, HPLC analysis is the conventional method for monitoring the phenolic removal during laccase enzyme reaction. This paper reports an investigation of the continuous UV absorbance follow-up of the laccase reaction with steam pretreated poplar hydrolysate.

RESULTS: Vanillin was used as a model substrate and lignocellulose xylose rich fraction (XRF) as a biologically complex substrate for laccase detoxification. The reaction was followed by HPLC-UV as well as by UV spectrometric measurements. Results suggest that the reaction can be successfully monitored by measuring the change of UV absorbance at 280 nm, without previous compound separation. In case of XRF experiments the spectrophotometric follow-up is especially useful, as HPLC analysis takes a long time and provides less information than in case of single substrates. The method seems to be suitable for optimization and process control.
\end{abstract}

CONCLUSION: The obtained results can help to construct a fast, easy and straightforward monitoring system for laccase-phenolic substrate reactions.

This article is protected by copyright. All rights reserved. 


\section{INTRODUCTION}

Laccase is a copper containing enzyme, belonging to the group of blue copper oxidases. ${ }^{1,2}$ It has been intensively studied because of its capability to oxidize a wide range of phenolics and non-phenolic substrates. ${ }^{2,3}$ For phenolic substrates the typical reaction has proven to be a one electron transfer oxidation with consecutive non-enzymatic coupling of the formed radical to oligomer, with a parallel reduction of molecular oxygen to water. ${ }^{3,4}$ This is one of the enzyme's main advantages as it can be regenerated by air instead of using additional chemicals, as in the case of peroxidase enzyme.

Several reviews have discussed the possible applications of laccases ${ }^{2,3,5-7}$, these include textile dye bleaching ${ }^{8,9}$, pulp bleaching ${ }^{2}$, food improvement ${ }^{10,11}$, bioremediation and wastewater treatment ${ }^{2}$, and even in organic synthesis and nanotechnology. ${ }^{2}$ Application of laccase enzyme for the removal of phenolics from lignocellulosic hydrolysate has also been investigated by Alvaro et al. ${ }^{12}$ and Jurado et al. ${ }^{13}$, who found increased ethanol productivity and better fermentability after the treatment.

Our research group is focused on environmentally friendly processes as well as alternative resources for bioprocesses. Laccase detoxification of lignocellulose substrate for microbial production processes is connected to both. This detoxification is often necessary to avoid inhibition of the microorganisms by the lignin derived compounds produced during pretreatment of lignocellulose. The main toxic products obtained after heat treatment are furans, phenolics and weak acids, of which the phenolics are considered to be the most toxic. 14

For effective control of the enzymatic process, the reaction has to be monitored. Usually, this can be done by simple ultra violet (UV) absorbance measurement of the substrate consumption or product formation. In case of laccase reaction, however, phenolics are the substrates as well as the products (often polyphenols). Moreover, measurement of the laccase reaction is even more complicated since the polymerized phenolic product is often insoluble and precipitates. ${ }^{15,16}$

This article is protected by copyright. All rights reserved. 
Several attempts to measure the size of the formed particles during enzyme catalyzed polymerization reactions have been published for phenolic substrates. Franciscon et al. investigated the laccase polymerization of aromatic amines, and they found that the particle size varies between 105-484 nm. ${ }^{17}$ Desentis-Mendoza et al. measured the time evolution of aggregates and found that the size reaches a maximum and declines afterwards. ${ }^{18}$

Yu et al. reported the formation of soluble dimers and one trimer in liquid phase with the phenol-peroxidase system, while other trimers and higher polymerization degree products were found in the precipitate. ${ }^{19}$ Lahtinen at al. ${ }^{20}$ studied the vanillyl alcohol-laccase reaction and found mostly dimer products, together with a minor amount of vanillin, but enzyme kinetics were not investigated. Fukuda et al. ${ }^{21}$ found products in the precipitate up to hexamers during bisphenol A-laccase reaction, but the products remaining in the liquid phase were not analyzed. Ganachaud et al. ${ }^{22}$ investigated the liquid phase of an indole-laccase system and found polymerization products until trimers.

For laccase reaction follow-up, several techniques have been used before, most often highperformance liquid chromatography (HPLC) with UV detection ${ }^{23-25}$, mass spectrometry (MS) detection ${ }^{12,26}$ or Folin-Ciocalteau method ${ }^{13,25}$, while visible (VIS) spectroscopy is usually reported in case of enzymatic decolorization of the liquid phase. ${ }^{8,9,27}$ Liquid chromatography measurements are capable to identify and measure substrates and products separately. UVVIS spectroscopy in decolorizing reactions measures the substrate concentrations, unless the formed products have absorbencies at the same wavelength. Folin-Ciocalteau method measures the sum of all phenolics, i.e., substrates and products.

Nilvebrant et al. applied HPLC-UV at $280 \mathrm{~nm}$ by using a C18 column as a method for phenolics analysis in lignocellulosic hydrolysates. ${ }^{28}$ They defined the amount of phenolics as the sum of peaks eluting after the furan peaks. It is important to note that during HPLC measurements, part of the absorbing reaction products will be filtered out during sample preparation.

If laccase reacts selectively with the UV absorbing phenolics in a sample, leaving every other UV absorbing compound unaffected, the previously discussed HPLC-peak-grouping method 
becomes very closely related to a simple UV absorbance measurement, as the absolute decrease of the absorbency value is equal to the decrease of the phenolic peaks described by Nilvebrant et al.. ${ }^{28}$

While each of the techniques has its disadvantages, the use of UV spectrometry for general follow-up, compared to the before mentioned methods is a simpler, faster and cheaper measurement. This method does not require additional treatment or chemicals. As a drawback, it is not capable to define separately neither the concentrations of phenolics nor the other compounds in the solution with absorbance at the measured wavelength.

In this paper, the goal is to investigate if UV spectrometry is a reliable measurement method for monitoring the laccase reaction of lignocellulose hydrolysate. This will be accomplished by investigating the reaction with vanillin as model substrate ${ }^{14}$ as well as with lignocellulose hydrolysate. In both cases UV spectrophotometric measurements will be compared to concentrations determined by HPLC-UV methodology. At the same time an attempt is made to determine the size of the particles and identify the formed reaction products.

\section{MATERIAL AND METHODS}

\section{Enzymatic reaction measurements}

Lignocellulosic xylose rich fraction (XRF). Poplar sawdust was donated by the saw mill Caluwaerts in Holsbeek, Belgium. The steam explosion was performed at Agro-Bio Tech in Gembloux, University of Liège. For every kg of sawdust a liter of water was added and treated at 25 bar $\left(224{ }^{\circ} \mathrm{C}\right)$ for 3 minutes before explosion. The slurry was centrifuged and stored at $-20{ }^{\circ} \mathrm{C}$. Prior to enzyme reaction, the $\mathrm{pH}$ was set to 7 with solid $\mathrm{KOH}$ (SigmaAldrich Corporation, St. Louis, MO, USA), and filtered through a $0.2 \mu \mathrm{m}$ syringe filter.

Enzyme solution. For the vanillin reaction $0.6 \mathrm{U} / \mathrm{ml}$ laccase solution was prepared (Laccase from Trametes versicolor, 13.6 U/mg, Sigma-Aldrich Corporation, St. Louis, MO, USA) with $0.1 \mathrm{M} \mathrm{pH} 6.9$ potassium phosphate (mono- and dibasic from Sigma-Aldrich Corporation, St. Louis, MO, USA) buffer, at least twelve hours before the measurement and stored at $4{ }^{\circ} \mathrm{C}$. The same buffer was used as a solvent in all experiments.

This article is protected by copyright. All rights reserved. 
For XRF detoxification measurements, 29.5 and $3.3 \mathrm{U} / \mathrm{ml}(10$ and $1.1 \mathrm{mg} / \mathrm{ml})$ laccase stock solutions were made.

Enzyme assay. The activity of $10 \mathrm{mg} / \mathrm{ml}$ enzyme solution was measured with 4-hydroxy-3,5dimethoxybenzaldehyde azine (syringaldazine) assay. ${ }^{29}$ In our laboratory, the method was adapted in the following way. The solution was prepared by mixing $1.7 \mathrm{ml}$ of $0.1 \mathrm{M}$ phosphate buffer $\mathrm{pH}$ 6.9, $0.1 \mathrm{ml}$ of the enzyme solution and $0.2 \mathrm{ml}$ of $0.1 \mathrm{mg} / \mathrm{ml}$ syringaldazine (Sigma-Aldrich Corporation, St. Louis, MO, USA) in methanol solution (VWR international, Radnor, PA, USA). The absorbance change was monitored at $530 \mathrm{~nm}$ for 4 minutes at $30{ }^{\circ} \mathrm{C}$ in a Genesys $10 \mathrm{UV}$ spectrometer (Thermo Fisher Scientific, Waltham, MA, USA). The enzyme concentration is expressed in $\mathrm{U} / \mathrm{ml}$ (molar extinction coefficient $=65000 \mathrm{l} /(\mathrm{mol} \mathrm{cm}))$, and represents the value in the reaction mixture during enzyme assay.

Laccase-vanillin reaction mixture. For the reaction, $1.8 \mathrm{mg}$ of vanillin substrate $(>97 \%$, Sigma-Aldrich Corporation, St. Louis, MO, USA) was dissolved in $50 \mathrm{ml} 0.1 \mathrm{M}$ phosphate buffer of pH 6.9 in an Erlenmeyer, and placed in a water bath shaker at $30^{\circ} \mathrm{C}$ and $150 \mathrm{rpm}$ to equilibrate. The reaction was initiated by adding $5 \mathrm{ml}$ of the enzyme solution to the mixture. Follow-up was done by sampling regularly.

Laccase-XRF reaction mixture. For $2.95 \mathrm{U} / \mathrm{ml}(1.0 \mathrm{mg} / \mathrm{ml})$ enzyme concentration, $5 \mathrm{ml}$ of $29.5 \mathrm{U} / \mathrm{ml}(10 \mathrm{mg} / \mathrm{ml})$ laccase solution was diluted to $50 \mathrm{ml}$ with the XRF liquid. For 0.3 $\mathrm{U} / \mathrm{ml}(0.1 \mathrm{mg} / \mathrm{ml})$ enzyme concentration, $4.5 \mathrm{ml}$ of $3.3 \mathrm{U} / \mathrm{ml}(1.1 \mathrm{mg} / \mathrm{ml})$ laccase solution and $0.5 \mathrm{ml}$ of buffer were diluted to $50 \mathrm{ml}$ with XRF. For $0.03 \mathrm{U} / \mathrm{ml}(0.01 \mathrm{mg} / \mathrm{ml})$ concentration $0.5 \mathrm{ml}$ of the $3.3 \mathrm{U} / \mathrm{ml}(1.1 \mathrm{mg} / \mathrm{ml})$ and $4.5 \mathrm{ml}$ buffer were diluted to $50 \mathrm{ml}$ with XRF. The mixture was stirred at $150 \mathrm{rpm}$ in a beaker at room temperature $\left(22 \pm 2{ }^{\circ} \mathrm{C}\right)$.

UV spectrometry and HPLC-UV measurement. Samples of the vanillin-laccase reaction were filtered through a $0.45 \mu \mathrm{m}$ syringe filter, either analyzed immediately by spectrometry or by HPLC-UV after adding $50 \mu \mathrm{l} 1 \mathrm{mg} / \mathrm{ml}$ azide (Sigma-Aldrich Corporation, St. Louis, MO, USA) to a $3 \mathrm{ml}$ aliquot to stop the reaction. HPLC-UV (Shimadzu SPD-M20A diode array

This article is protected by copyright. All rights reserved. 
detector, Shimadzu corp., Kyoto, Japan), with methanol and 1\% v/v acetic acid solution (Sigma-Aldrich Corporation, St. Louis, MO, USA) as a mobile phase on a Luna $5 \mu \mathrm{m}$ C18(2) 100 Å column (Phenomenex, Torrance, CA, USA). Every analysis was performed at $1 \mathrm{ml} / \mathrm{min}$ flowrate. The mobile phase gradient was: 0-5 $\min 10 \%$ methanol, 5-35 min gradient to $50 \%$, 35-35.1 min gradient to $100 \%$, 35.1-40 min $100 \%$. The concentrations of the phenolics are expressed in vanillin equivalent, which is the concentration of vanillin that has the same peak area as the measured compound. The time required for filtration before azide addition and HPLC measurement was negligible compared to the time of the reaction. Azide was not added to the UV measurement due to its strong absorption in the UV range that would interfere with the spectrometric measurements of the phenolics. A blank sample was measured in the same way by mixing $3 \mathrm{ml}$ of buffer with $50 \mu \mathrm{l}$ of azide solution for HPLC and without azide for spectrometry.

For laccase-XRF analysis the sample was filtered through a $0.45 \mu \mathrm{m}$ syringe filter, diluted 100 times with $\mathrm{NaOH}$ pH 10.4 solution to stabilize pH and measured with spectrophotometry. For HPLC analysis two different mobile phase gradients were used, both with methanol and 1 $\% \mathrm{v} / \mathrm{v}$ acetic acid solution. Gradient A was applied to have a fast analysis and to determine the total phenolics, as they elute as a region of unresolved peaks after the 5-(hydroxymethyl)-2furaldehyde (HMF) peak. The gradient profile was 0-5 min $10 \%$ methanol, 5-9.3 min gradient to $84.5-15.5 \%$, 9.3-9.4 min gradient to $100 \%$, 9.4-17 min $100 \%$. With Gradient B the elution was slower and it was used for detailed analysis of the samples with a good separation of most of the peaks. The gradient profile was 0-15 min $10 \%, 15-55$ min gradient to $30 \%$, 55-70.1 min gradient to $100 \%, 70.1-80$ min $100 \%$. All the measurements are quantified in vanillin equivalents.

Vanillin-laccase products identification with Preparative HPLC-MS. The fractionation of the sample was done with semi-preparative HPLC (Waters corp., Milford, MA, USA) with a binary pump, automatic injection sampler, diode array detector and triple quad detector mass spectrometer (TQD-MS, Waters corp., Milford, MA, USA) and an automatic fraction collector to isolate the HPLC fractions. The parameters of the MS detector were: $100{ }^{\circ} \mathrm{C}$

This article is protected by copyright. All rights reserved. 
temperature, desolvation at $200{ }^{\circ} \mathrm{C}$ at $250 \mathrm{l} / \mathrm{h}$ gas flow and $50 \mathrm{l} / \mathrm{h}$ cone gas flow, the applied capillary/cone/extractor/RF lens voltages were 3k/60/3/0 V. The detector was working in positive mode. A Luna $5 \mu \mathrm{m}$ C18(2) column with large internal diameter (250 x $10 \mathrm{~mm})$ was used. The injection volume was $3 \mathrm{ml}$ and the elution rate was $3 \mathrm{ml} / \mathrm{min}$, with methanol and $0.1 \%$ acetic acid solution used in a gradient elution as follows: 0-15 min $50 \%$ methanol, $15-$ 20 min gradient to $100 \%, 20-25 \min 100 \%$. The fractions collected were dried in a vacuum centrifuge (RVC 2-18 Rotational Vacuum Concentrator, Martin Christ, Osterode am Harz, Germany) at $50{ }^{\circ} \mathrm{C}$ and $1200 \mathrm{rpm}$ until the liquid was completely evaporated. 1 mg solids was brought into $1 \mathrm{ml}$ water or methanol.

Particle size measurements for XRF-laccase reaction. Particle size measurements (Zetasizer Nano, Malvern Instruments Ltd., Worcestershire, UK) were performed with 2.95 $\mathrm{U} / \mathrm{ml}$ laccase-XRF reaction solutions. Both enzyme and XRF solution were filtered $(0.45 \mu \mathrm{m})$ separately previous to the reaction, and the two compounds were merged in an Erlenmeyer. Three samples were taken; at 0,3 and 6 hours. The first sample was measured immediately; the other two samples were prepared in three different ways, i.e., without filtration and filtrations with $0.45 \mu \mathrm{m}$ and $0.2 \mu \mathrm{m}$ syringe filter. Sampling was done in triplicate; each sample was subjected to 15 consecutive measurements, therefore each datapoint is an average of 45 measurements.

\section{RESULTS AND DISCUSSION}

Laccase detoxification was followed up by spectrophotometry on different substrates, i. e., vanillin as a model compound and the lignocellulose hydrolysate system.

\section{VANILLIN-LACCASE REACTION}

\section{Comparing spectrometry with HPLC}

Visual inspection of the vanillin-laccase reaction mixture revealed that it was transparent at the beginning of the experiment and turned to a slight opal yellow color after about one hour reaction time. The appearing yellow color of the laccase-vanillin reaction mixture is caused

This article is protected by copyright. All rights reserved. 
by the formed dissolved products, while the opal effect is expected to be caused by the formed particles, as the color remains and the opacity disappears after $0.45 \mu \mathrm{m}$ filtration.

The vanillin concentrations, measured after filtration by UV and HPLC, decrease over time (see Figure 1), which was expected as the substrate was converted to oligomers. These products precipitate and the formed particles cause scattering. The unfiltered UV measurements first slightly increased and then faintly decreased, probably due to sedimentation afterwards. Since reaction monitoring by UV absorbance without filtering is not appropriate, no further experiments were done with unfiltered samples. The results of the filtered samples were promising so further experiments were conducted, as the UVmeasurements and the HPLC concentrations followed a similar decreasing trend during the reaction.

UV-spectrophotometric measurements. Vanillin has absorption peaks at 280 and $315 \mathrm{~nm}$ and both could be used for reaction monitoring as they are declining with time (data not shown). By this time the vanillin concentration measured by HPLC is under $2 \%$ of the starting value, while the final absorbance is still about $40 \%$ of the initial absorbancy. Part of this absorbancy must be derived from the formed products, but scattering effect of particles with a size of $0.45 \mu \mathrm{m}$ or smaller, can also play a role as they are not filtered out.

HPLC measurements. A typical HPLC-UV chromatogram from a sample of the laccasevanillin reaction taken after 180 min can be seen on Figure 2. The azide peak elutes at 4.5 min, the vanillin peak after 22.5 min. During the reaction two peaks appear at 35 and 35.5 min. The other peaks are the background derived from the buffer solution. As soon as the reaction starts, the product peaks are increasing while the vanillin concentration as well as the summated HPLC peak area (Figure 3A) is decreasing. The total HPLC peak area is visualized to enable a better comparison with the measured UV spectrum and includes substrate, products and background, and excludes the azide peak. Product B is formed faster than A during the course of the reaction, but later on its concentration decreases while A is still increasing until at least 300 minutes (Figure 3B).

This article is protected by copyright. All rights reserved. 
The number of products measured correlates well with the results of Lahtinen et al. ${ }^{20}$, who investigated the vanillin alcohol-laccase reaction and found that the two main products were different dimers, one with an aromatic ring-aromatic ring bound and the other with an ether bound between the two aromatic rings, however the product concentration change in time was not investigated, as it is done in this work. From the evolution of both products in Figure 3B, it seems that only product B is reacting further, while product A seems not to or at a much lower rate. The fate of the reaction product from B is most probably polymerization and precipitation, as no additional product peaks appear.

Additionally, it is important to note that the absorption spectrum of vanillin is dependent on the $\mathrm{pH}$ of the solution, as often happens with phenolics. ${ }^{30}$ The vanillin-laccase reaction was performed in buffer, so the $\mathrm{pH}$ remained stable during the UV measurements.

Product identification. HPLC-MS fractionation was performed in an attempt to separate the products and identify them. Chromatograms recorded during the fractionation of the vanillinlaccase reaction mixture are shown on Figure 4. The overall UV absorbency, measured after 120 min of reaction time (Figure 4A), is closely related to Figure 2 that was obtained after $180 \mathrm{~min}$ at $280 \mathrm{~nm}$. The first peak is vanillin at $11 \mathrm{~min}$, whereas the second and third peaks are two product peaks at $18.5 \mathrm{~min}$ and $19.5 \mathrm{~min}$, respectively. The absorption spectrum taken at a retention time of $19 \mathrm{~min}$ from the second product shows three main maxima at 206; 236 and $305 \mathrm{~nm}$ (Figure 4F). Figure 4B represents the mass spectrum monitored at $301 \mathrm{~m} / \mathrm{z}$, which is the deprotonated dimer mass.

From the fragmentation chromatogram (Figure 4E) filtered on $301 \mathrm{~m} / \mathrm{z}$, it was confirmed that the two products were dimers. This is the same as in the work of Lahtinen et al.. ${ }^{20}$ The product peaks only differed in terms of intensity of fragments, but they had the same fragmentation pattern. The two main m/z-peaks, 285 and 286, found in the fragmentation chromatogram are expected to be the results of radical cleavages. Radical cleavage was suggested before by Cuyckens and Claeys ${ }^{31}$ in case of flavonoids. They assumed that the negative charge on the neighboring phenolic ring enhances the stability of the remaining radical, thus a methyl radical will leave the molecule and a 286 mass unit negatively charged

This article is protected by copyright. All rights reserved. 
fragment is formed. The 285 fragment can be a result of a ring opening and a loss of extra $\mathrm{H}$ radical. As shown by Navarra ${ }^{32}$, the free electron of radicals can delocalize to the oxygen of the phenol as well as in ortho-direction on the ring, though depending on the exact structure, other possibilities are described.

The mass spectrum at $151 \mathrm{~m} / \mathrm{z}$ is visible on Figure 4C. This value is only appearing at the time the vanillin elutes, but it seems that no molecules of this size are obtained after ionization of dimers. Figure 4D shows the overall mass spectrum during fractionation. The majority of the total mass present in the analytical sample is leaving the column after 4-10 minutes. No peak was found at $451 \mathrm{~m} / \mathrm{z}$, which would correspond to protonated trimers, although it is not clear if they are not produced, or if the low solubility makes them precipitate faster.

These findings are different to the results obtained for the phenol-peroxidase system by Yu et al.. ${ }^{19}$ In their work all dimers were subjected to further polymerization by the peroxidase enzyme and the highest polymerization degree reached was that of a trimer. This was not true in our experiment (Figure 3) since only product B reacted further with laccase. Product B's concentration reached a maximum in 50 minutes and then started to decline. According to the WATERNT ${ }^{\mathrm{TM}}$ software from the US Environmental Protection Agency, which estimates water solubility directly using a "fragment constant" method from the chemical structure, the dimer solubility decreases by $99 \%$ compared to monomer, and trimer solubility decreased again with $98 \%$ compared to dimers. Although the method is an approximation, the rates are an indication for the solubility decrease, and can explain why trimers were undetected in the solution.

After HPLC fractionation, the collected product samples were dried by vacuum centrifugation. The remaining solid was technically insoluble in both water and methanol. This suggests that the solid fraction underwent further reaction, possibly polymerization ${ }^{33}$, or that the solubility of products is very low even in methanol.

This article is protected by copyright. All rights reserved. 


\section{XRF-LACCASE REACTION.}

Vanillin-laccase reaction is an XRF model system, which is good for understanding the process, whereas XRF is a real biological sample with a wide spectrum of compounds. XRF is obtained by lignocellulose pretreatment and contains sugars, but also lignin-derived phenolics that are toxic for the subsequent application of the sugars by microorganisms in fermentation. Spectrophotometric follow-up of the laccase detoxification reaction would be beneficial for industrial use, as it is simple and robust.

The hydrolysate obtained after steam explosion had a $\mathrm{pH}$ value of 4 and was neutralized before the laccase reaction. During this, the color of the liquid turned to deeper brown. Three different enzyme concentrations were used, i.e., 2.95, 0.3 and $0.03 \mathrm{U} / \mathrm{ml}$. The reaction mixture was transparent at the start and turned milky over time. The speed of this change was faster at higher enzyme concentrations. During the reaction, slight acidification of the reaction mixture was observed by a decrease of pH by approximately 0.4 units.

UV-spectrophotometric measurements. The XRF had a single UV absorption peak at 280 $\mathrm{nm}$, which was decreasing over time with different rates depending on the enzyme dosage, fairly linearly (data not shown). It is important to note that the spectrum is strongly dependent on the $\mathrm{pH}$, i.e., at $\mathrm{pH} 4$ the peak is $32 \%$ lower than at $\mathrm{pH} 10.4$ for the sample taken at $0 \mathrm{~min}$ reaction time. Since the $\mathrm{pH}$ changes slightly during the reaction and the original samples absorbance is around 100 , it was diluted 100 times in triplicate with $\mathrm{NaOH}$ solution to stabilize the $\mathrm{pH}$ and to achieve absorbance values under 2 units. Standard deviations from the triplicates were under $2.0 \%$. While filtering the samples of the vanillin-laccase reaction caused a big difference in the spectrophotometric measurements (see Figure 1), the absorption difference between not filtering, filtering with 0.2 and with $0.45 \mu \mathrm{m}$ pore size was much less for the XRF-laccase reaction: compared to $0.2 \mu \mathrm{m}$ filtered samples, filtering with $0.45 \mu \mathrm{m}$ resulted in around $5 \%$ higher absorbancy and unfiltered samples gave $10 \%$ higher values. This difference was stable during the course of the reaction. Probably this is due to the higher phenolics concentration in the XRF and subsequent 100 times dilution that reduces the particles concentration and hence the scattering effect.

This article is protected by copyright. All rights reserved. 
Quantifying the different compounds from the UV spectrum is impossible. It is known that Furan-2-carbaldehyde (furfural) and HMF peaks have a significant absorbance at $280 \mathrm{~nm}$, together with the targeted phenolics, so their presence is decreasing the sensitivity of the measurements (data not shown). In an industrial process their concentration is minimized during pretreatment as they are formed by degradation of the processes' most valuable products, monomer sugars.

HPLC measurements. The fast technique (Gradient A) identifies the following compounds, i.e., furfural, HMF and phenolics. Their initial concentration in the XRF gave rise to 12, 18 and $60 \%$ of the UV absorbance respectively, but ratios measured may change with pH due to the extinction coefficient dependency of $\mathrm{pH}$ (data not shown). For $2.95 \mathrm{U} / \mathrm{ml}$ enzyme concentration, Figure 5 shows four chromatograms with Gradient B elution taken at different times (0, 3, 6, 24 h). Gradient B separates the phenolics to ten bigger peaks. From these, six peaks and afterwards, eight peaks disappeared after, respectively, 180 and 360 min reaction time. The two remaining peaks, i.e., the second and the fourth peak at 16 and 19 minutes, finally had $88 \%$ and $83 \%$ of their starting concentration respectively, and $47 \%$ and $5 \%$ of the starting total phenolics peak area.

As discussed above, the decrease in phenolic peaks is clearly visible on Figure 5, but also formation of a broad flat peak can be distinguished at higher methanol concentrations in the mobile phase (more hydrophobic properties). Most probably, these are the product peaks of the reaction, i.e., dimers and potentially trimers. Their number can be estimated in the following way: if there are 10 different monomers and two bounding types (ring-ring and ether bound) are assumed, the number of possible dimer products is at magnitude of hundreds, possible trimers are several thousands. It will be impossible to determine them separately. As the polymerization degree rises, the aromatic ring will have a bigger impact on the properties and the side-chain functional groups that are bounded will have less, which explains the elution at higher hydrophobicity. In monitoring detoxification, these compounds will be measured as phenolics with both the 'fast' HPLC and the spectrophotometric measurements.

This article is protected by copyright. All rights reserved. 
However, researchers have proven that the polymerization products, obtained by enzyme treatment of phenolics, have reduced toxicity. ${ }^{15}$

The results of laccase-XRF reactions for the three different enzyme concentrations are presented in Figure 6. HMF peaks increased slightly, while furfural was slightly decreasing with a rate independent from the enzyme concentration. This is caused by evaporation, as the enzyme concentration did not cause furfural decrease, but stirring and temperature did (results not shown). Furfural decrease through vacuum evaporation was reported before in literature.

${ }^{34}$ The grouped phenolics peaks were decreasing during the whole measurement at different rate and faster with higher enzyme dosage.

Comparing HPLC and spectrophotometric measurements. For both measurement techniques the same samples were used to enable reliable comparison. Figure 7 shows the velocity in decrease of phenolics for both HPLC and UV measurements for all three enzyme concentrations, calculated from the vanillin calibration curve, and thus expressed in vanillin equivalents. After 6 hours of reaction with enzyme concentrations of 2.95, 0.3 and $0.03 \mathrm{U} / \mathrm{ml}$, the total phenolics content, measured by HPLC, dropped with 1.9, 0.4 and $0.0 \mathrm{~g} / \mathrm{l}$ respectively, which corresponds with $55 \%$, $89 \%$ and $99 \%$ of the initial concentration and a reaction velocity of $0.30,0.07$ and $0.00 \mathrm{~g} / \mathrm{l} \cdot \mathrm{h}$. For spectrophotometry, the velocity of the reaction calculated from the decrease of absorbance was $0.39,0.23$ and $0.06 \mathrm{~g} / \mathrm{l} \cdot \mathrm{h}$ respectively with a remaining absorbance of $86 \%, 91 \%$ and $97 \%$. The absorbance decreases obtained by UV spectrophotometry are linear, as they are for the HPLC measurements, and as could be expected from the Michaelis-Menten equation for high substrate concentrations.

It can be seen that the enzyme activity measured as phenolics removed by time is not the same for HPLC and UV measurements. Also the influence of the different enzyme concentrations is not constant, although the figure shows that for both measurement techniques, the enzyme activity increases with increasing enzyme concentration. A difference between the researched measurement techniques is that at the lowest enzyme dosage, where the HPLC measurement does not show any decrease in phenolics, that the UV measurement

This article is protected by copyright. All rights reserved. 
(see Figure 7) shows a slight decrease. This error is expected to be caused by furfural evaporation, since it is the only compound that is changing significantly (see Figure 6). This will be the same for all three enzyme concentrations and can be considered to be in the range of the measurement error. It is known, that different phenol measurement methods may result in different values. This was reported before when HPLC and Folin method were compared (around $20 \%$ difference) ${ }^{28}$, although both methods are still considered valid. The results show that UV absorbency can be used to compare detoxification results and optimize processes.

Particle size distribution. After the XRF-laccase reaction, probably a polydisperse solution was obtained. Results measured with the Zetasizer Nano instrument have to be discussed with caution because the software is configured for monodisperse solutions.

During reaction, the first measurement point at zero hours showed that some particles were present. This was considered as the background. The samples obtained by different pore size filtrations after three and six hours reaction show a significant amount of particles at every size range, i.e., above $0.45 \mu \mathrm{m}$, under $0.45 \mu \mathrm{m}$ as well as below $0.2 \mu \mathrm{m}$. The 'derived count rate', that is an intensity type parameter returned by the software for every measurement, is correlated to both the size and concentration of the particles and can be used to compare concentrations in the same particle size-range. For the unfiltered samples, sedimentation appears, which is also indicated by the software and can be seen from the increasing derived count rate by time, and thus the increasing concentration of particles (see Table 1). The filtered samples either produced good quality measurements or they were marked as polydisperse by the software. The mean particle diameter sometimes differs significantly between the three replicates. This is caused by the polydispersity. It can be concluded, that during the reaction the particle concentration is increasing in all three size ranges, as can be seen from the two to three folds bigger derived count rates. The mean particle size is growing in the unfiltered samples (approximately from 600 to $1200 \mathrm{~nm}$ ) and in the $0.2 \mu \mathrm{m}$ filtered samples (approximately from 2 to $11 \mathrm{~nm}$ ). But for the size range under $0.45 \mu \mathrm{m}$, the mean diameter is decreasing from around 200 to a rather low value, i.e., around $10 \mathrm{~nm}$. A possible

This article is protected by copyright. All rights reserved. 
explanation is that the particles grew over the $0.45 \mu \mathrm{m}$ limit from $3 \mathrm{~h}$ till $6 \mathrm{~h}$ reaction time and are filtered out, but this conclusion is very uncertain.

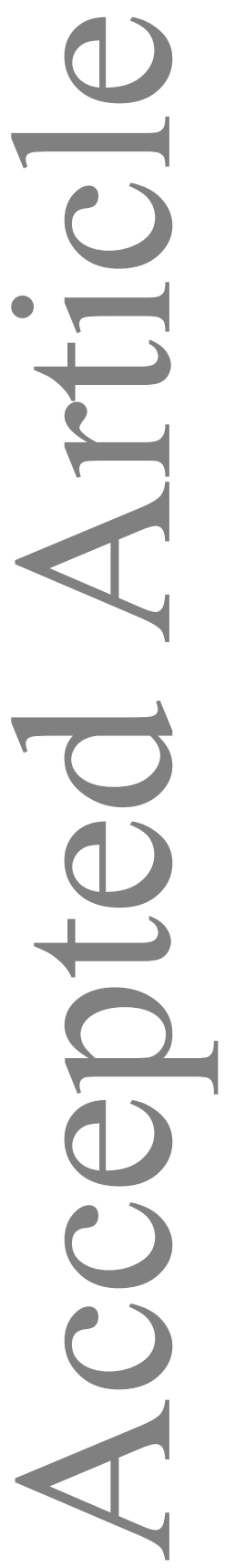

This article is protected by copyright. All rights reserved. 


\section{GENERAL CONCLUSIONS}

Two possible laccase applications and their spectrophotometric follow-up were investigated, i.e., the vanillin-laccase reaction is applied as a model system for the XRF-laccase reaction and laccase-lignocellulose hydrolysate system as a detoxification process.

The results obtained in this work suggest that UV absorbance measurements can be used for end-point as well as enzyme activity determination (time evolution) of the laccase catalyzed reaction with phenolics as substrates. Direct calculation of precise, separate concentrations is often impossible even with HPLC, due to the number of substrates and formed products. Several difficulties appear, such as, changing ratios of the formed dimer products during the course of the reaction, the remaining absorbance of the reaction products and the absorbency change caused by $\mathrm{pH}$ shift. Dilution before measurement solves the $\mathrm{pH}$ shift problem and is often required because of the high starting concentrations. Compared to HPLC measurements, spectrophotometric follow-up of the laccase-reaction is a possible substitute because HPLC measurement is slower, more expensive and harder to automatize. Moreover, efficient optimization of the laccase-phenolics reaction for industrial application is allowed by this technique.

The more in depth analysis of the laccase reactions in this research suggest that only dimers remain dissolved in the liquid phase during the laccase vanillin reaction, while higher polymerization degree products most probably precipitate. Also the formed dimers can have very different affinity towards further reaction.

It was proven that during laccase-XRF reaction hydrophilic compounds are converted to more and more hydrophobic products as time goes on. The products are mostly in lower concentrations and are similar in terms of hydrophobicity, which can be explained with the higher aromatic content compared to functional groups as the polymerization degree rises.

Generally, UV spectroscopy can be considered a valuable alternative for follow-up of phenolic removal during detoxification reactions.

This article is protected by copyright. All rights reserved. 


\section{ACKNOWLEDGEMENTS}

This research is financed by the University of Antwerp (project number 15 FA100 002).

We acknowledge the help of dr. Rica Capistrano (NatuRA - University Antwerpen) in connection to mass-spectrometry measurements, dr. Paul Vanderauwera (GERM - University Antwerpen), and Karel de Grote-Hogeschool for the analysis and equipment.

This article is protected by copyright. All rights reserved. 


\section{REFERENCES}

1. Thurston CF, The structure and function of fungal laccases. Microbiology 140 :19-26 (1994). DOI: 10.1099/13500872-140-1-19

2. Kunamneni A., Plou FJ, Ballesteros A., Alcalde M, Laccases and their applications: a patent review. Recent Pat. Biotechnol. 2 :10-24 (2008).

3. Durán N, Rosa MA, D’Annibale A., Gianfreda L, Applications of laccases and tyrosinases (phenoloxidases) immobilized on different supports: a review, Enzyme Microb. Technol. 31 :907-931 (2002). DOI:10.1016/S0141-0229(02)00214-4

4. Busca G, Berardinelli S, Resini C, Arrighi L, Technologies for the removal of phenol from fluid streams: A short review of recent developments, J. Hazard. Mater. 160 :265-288 (2008). DOI:10.1016/j.jhazmat.2008.03.045

5. Madhavi V, Lele SS, Laccase: properties and applications, BioResources 4 :16941717 (2009).

6. Fernández-Fernández M, Sanromán M, Moldes D, Recent developments and applications of immobilized laccase, Biotechnol. Adv. 31 :1808-1825 (2013). DOI:10.1016/j.biotechadv.2012.02.013

7. Duran N, Esposito E, Potential applications of oxidative enzymes and phenoloxidaselike compounds in wastewater and soil treatment: a review, Appl. Catal., B 28 :83-99 (2000). DOI:10.1016/S0926-3373(00)00168-5

8. Peralta-Zamora P, Pereira CM, Tiburtius ER, Moraes SG, Rosa MA, Minussi RC, Durán N, Decolorization of reactive dyes by immobilized laccase, Appl. Catal., B 42 :131-144 (2003). DOI:10.1016/S0926-3373(02)00220-5

9. Champagne PP, Ramsay JA, Reactive blue 19 decolouration by laccase immobilized on silica beads, Appl. Microbiol. Biotechnol. 77 :819-823 (2007). DOI:10.1007/s00253-007$1208-1$

This article is protected by copyright. All rights reserved. 
10. Piacquadio P, De Stefano G, Sammartino M, Sciancalepore V, Phenols removal from apple juice by laccase immobilized on $\mathrm{Cu}$ 2+-chelate regenerable carrier, Biotechnol. Tech. 11 :515-517 (1997). DOI:10.1023/A:1018418201268

11. Lante A, Crapisi A, Pasini G, Zamorani A, Spettoli P, Immobilized Laccase for Must and Wine Processinga, Ann. N. Y. Acad. Sci. 672 :558-562 (1992). DOI: 10.1111/j.17496632.1992.tb35669.x

12. Alvira P, Moreno AD, Ibarra D, Sáez F, Ballesteros M, Improving the fermentation performance of saccharomyces cerevisiae by laccase during ethanol production from steam-exploded wheat straw at high-substrate loadings, Biotechnol. Prog. 29 :74-82 (2013). DOI: $10.1002 / b t p r .1666$

13. Jurado M, Prieto A, Martínez-Alcalá Á, Martínez ÁT, Martínez MJ, Laccase detoxification of steam-exploded wheat straw for second generation bioethanol, Bioresour. Technol. 100 :6378-6384 (2009). DOI:10.1016/j.biortech.2009.07.049

14. Jönsson, LJ, Palmqvist E, Nilvebrant NO, Hahn-Hägerdal B, Detoxification of wood hydrolysates with laccase and peroxidase from the white-rot fungus Trametes versicolor, Appl. Microbiol. Biotechnol. 49 :691-697 (1998).

15. Ward G, Hadar Y, Dosoretz CG, Lignin peroxidase-catalyzed polymerization and detoxification of toxic halogenated phenols, J. Chem. Technol. Biotechnol. 78 :1239-1245 (2003). DOI: 10.1002/jctb.933

16. Steevensz A, Al-Ansari MM, Taylor KE, Bewtra JK., Biswas N, Oxidative coupling of various aromatic phenols and anilines in water using a laccase from Trametes villosa and insights into the 'PEG effect', J. Chem. Technol. Biotechnol. 87 :21-32 (2012). DOI: 10.1002/jctb.2734

17. Franciscon E, Piubeli F, Fantinatti-Garboggini F, Ragagnin de Menezes C, Serrano Silva I, Cavaco-Paulo A, Durrant LR, Polymerization study of the aromatic amines generated by the biodegradation of azo dyes using the laccase enzyme, Enzyme Microb. Technol. 46 :360-365 (2010). DOI:10.1016/j.enzmictec.2009.12.014

This article is protected by copyright. All rights reserved. 
18. Desentis-Mendoza RM, Hernández-Sánchez H, Moreno A, Rojas del CE, ChelGuerrero L, Tamariz J, Jaramillo-Flores ME, Enzymatic Polymerization of Phenolic Compounds Using Laccase and Tyrosinase from Ustilago m aydis, Biomacromolecules 7 :1845-1854 (2006). DOI: 10.1021/bm060159p

19. Yu J, Taylor KE, Zou H, Biswas N, Bewtra JK, Phenol conversion and dimeric intermediates in horseradish peroxidase-catalyzed phenol removal from water, Environ. Sci. Technol. 28 :2154-2160 (1994). DOI: 10.1021/es00061a025

20. Lahtinen M, Heinonen P, Oivanen M, Karhunen P, Kruus K, Sipilä J, On the factors affecting product distribution in laccase-catalyzed oxidation of a lignin model compound vanillyl alcohol: experimental and computational evaluation, Org. Biomol. Chem. 11 :54545464 (2013). DOI: 10.1039/C3OB40783G

21. Fukuda T, Uchida H, Suzuki M, Miyamoto H, Morinaga H, Nawata H, Uwajima T, Transformation products of bisphenol A by a recombinant Trametes villosa laccase and their estrogenic activity, J. Chem. Technol. Biotechnol. 79 :1212-1218 (2004). DOI: 10.1002/jctb.1115

22. Ganachaud C, Garfagnoli V, Tron T, Iacazio G, Trimerisation of indole through laccase catalysis, Tetrahedron Lett. 49 :2476-2478 (2008). DOI:10.1016/j.tetlet.2008.02.021

23. Shuttleworth KL, Bollag JM, Soluble and immobilized laccase as catalysts for the transformation of substituted phenols, Enzyme Microb. Technol. 8 :171-177 (1986). DOI:10.1016/0141-0229(86)90108-0

24. Salis A, Pisano M, Monduzzi M, Solinas V, Sanjust E, Laccase from $<\mathrm{i}>$ Pleurotus sajor-caju $</ \mathrm{i}>$ on functionalised SBA-15 mesoporous silica: Immobilisation and use for the oxidation of phenolic compounds, J. Mol. Catal. B: Enzym. 58 :175-180 (2009). DOI:10.1016/j.molcatb.2008.12.008

25. Kolb M, Sieber V, Amann M, Faulstich M, Schieder D, Removal of monomer delignification products by laccase from Trametes versicolor, Bioresur. Technol. 26 :298-304 (2011). DOI:10.1016/j.biortech.2011.11.080

This article is protected by copyright. All rights reserved. 
26. Galliker P, Hommes G, Schlosser D, Corvini PFX, Shahgaldian P, Laccase-modified silica nanoparticles efficiently catalyze the transformation of phenolic compounds, J. Colloid Interface Sci. 349 :98-105 (2010). DOI:10.1016/j.jcis.2010.05.031

27. Osma JF, Toca-Herrera JL, Rodríguez-Couto S, Transformation pathway of Remazol Brilliant Blue R by immobilised laccase, Bioresour. Technol. 101 :8509-8514 (2010). DOI:10.1016/j.biortech.2010.06.074

28. Nilvebrant NO, Reimann A, Larsson S, Jönsson LJ, Detoxification of Lignocellulose Hydrolysates with Ion-Exchange Resins, Appl. Biochem. Biotechnol. 91 :1-3 (2001).

29. Johannes C, Majcherczyk A, Laccase activity tests and laccase inhibitors, J. Biotechnol. 78 :193-199 (2000). DOI:10.1016/S0168-1656(00)00208-X

30. Manole A, Herea D, Chiriac H, Melnig V, Laccase activity determination, Cuza University Scientific Annals Lasi 4 :17-24 (2008).

31. Cuyckens F, Claeys M, Mass spectrometry in the structural analysis of flavonoids, $J$. Mass Spectrom. 39 :1-15 (2004). DOI: 10.1002/jms.585

32. Navarra C, Goodwin C, Burton S, Danieli B, Riva S, Laccase-mediated oxidation of phenolic derivatives, J. Mol. Catal. B: Enzym. 65 :52-57 (2010). DOI:10.1016/j.molcatb.2009.12.016

33. Rittstieg K, Suurnakki A, Suortti T, Kruus K, Guebitz G, Buchert J, Investigations on the laccase-catalyzed polymerization of lignin model compounds using size-exclusion HPLC, Enzyme Microb. Technol. 31 :403-410 (2002). DOI:10.1016/S0141-0229(02)00102-3

34. Larsson S, Reimann A, Nilvebrant NO, Jönsson LJ, Comparison of different methods for the detoxification of lignocellulose hydrolyzates of spruce, Appl. Biochem. Biotechnol, 77: 91-103 (1999). DOI: 10.1385/ABAB:77:1-3:91

This article is protected by copyright. All rights reserved. 
Table 1. Particle size measurements during the XRF-laccase reaction with $2.95 \mathrm{U} / \mathrm{ml}$ enzyme concentration. Samples were taken at 0,3 and $6 \mathrm{~h}$, with three different sample preparation: without filtration, with $0.45 \mu \mathrm{m}$ and $0.2 \mu \mathrm{m}$ pore size filtration. Each point is the average of 45 measurements. Derived count rate is a measure for both particle concentration and size.

\begin{tabular}{|l|lllll|}
\hline $\begin{array}{l}\text { Time } \\
{[\mathrm{h}]}\end{array}$ & $\begin{array}{l}\text { Filtration } \\
{[\mu \mathrm{m}]}\end{array}$ & $\begin{array}{l}\text { Mean particle } \\
\text { size }[\mathrm{nm}]\end{array}$ & $\begin{array}{l}\text { Std } \\
{[\mathrm{nm}]}\end{array}$ & $\begin{array}{l}\text { Derived count rate } \\
{[-]}\end{array}$ & $\begin{array}{l}\text { Details } \\
{[-]}\end{array}$ \\
\hline 0 & 0.2 & 2.0 & 0.98 & 702 & polydisperse \\
& 0.2 & 1.8 & 0.95 & 708 & polydisperse \\
& 0.2 & 1.4 & 0.75 & 749 & polydisperse \\
\hline 3 & non & 661 & 269 & 139961 & sedimenting \\
& non & 550 & 100 & 135559 & sedimenting \\
& non & 837 & 336 & 132876 & sedimenting \\
\cline { 2 - 5 } & 0.45 & 188 & 71 & 6051 & good quality \\
& 0.45 & 195 & 85 & 6253 & good quality \\
& 0.45 & 201 & 93 & 6145 & good quality \\
\cline { 2 - 6 } & 0.2 & 2.1 & 1.1 & 1645 & polydisperse \\
& 0.2 & 2.8 & 1.2 & 1537 & polydisperse \\
& 0.2 & 2.5 & 1.1 & 1566 & polydisperse \\
\hline 6 & non & 1244 & 320 & 305390 & sedimenting \\
& non & 1231 & 358 & 284748 & sedimenting \\
& non & 1493 & 381 & 278445 & sedimenting \\
\cline { 2 - 6 } & 0.45 & 4.4 & 1.4 & 11228 & polydisperse \\
& 0.45 & 8.6 & 2.6 & 11260 & polydisperse \\
& 0.45 & 7.2 & 2.7 & 11392 & polydisperse \\
\cline { 2 - 6 } & 0.2 & 10.2 & 9.5 & 5429 & polydisperse \\
& 0.2 & 14.4 & 12.8 & 5366 & good quality \\
& 0.2 & 9.2 & 9.5 & 5354 & polydisperse \\
\hline \multirow{6}{*}{0.2} & & & &
\end{tabular}

This article is protected by copyright. All rights reserved. 


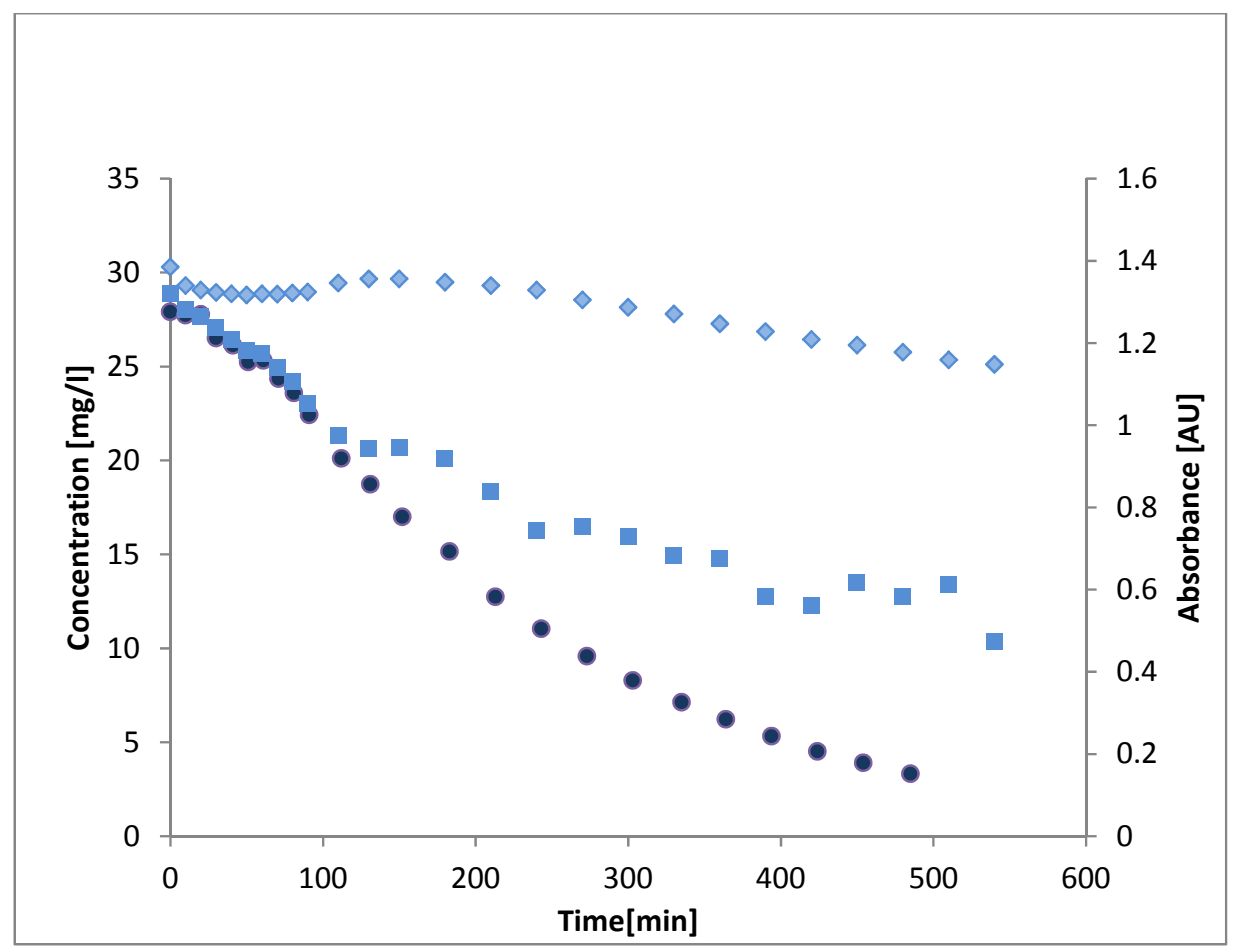

Figure 1. Vanillin concentration during reaction with laccase followed up by $(\diamond)$ UV measurement without filtration, ( $\bullet$ ) UV measurement after filtration and (•) HPLC measurement.

This article is protected by copyright. All rights reserved. 


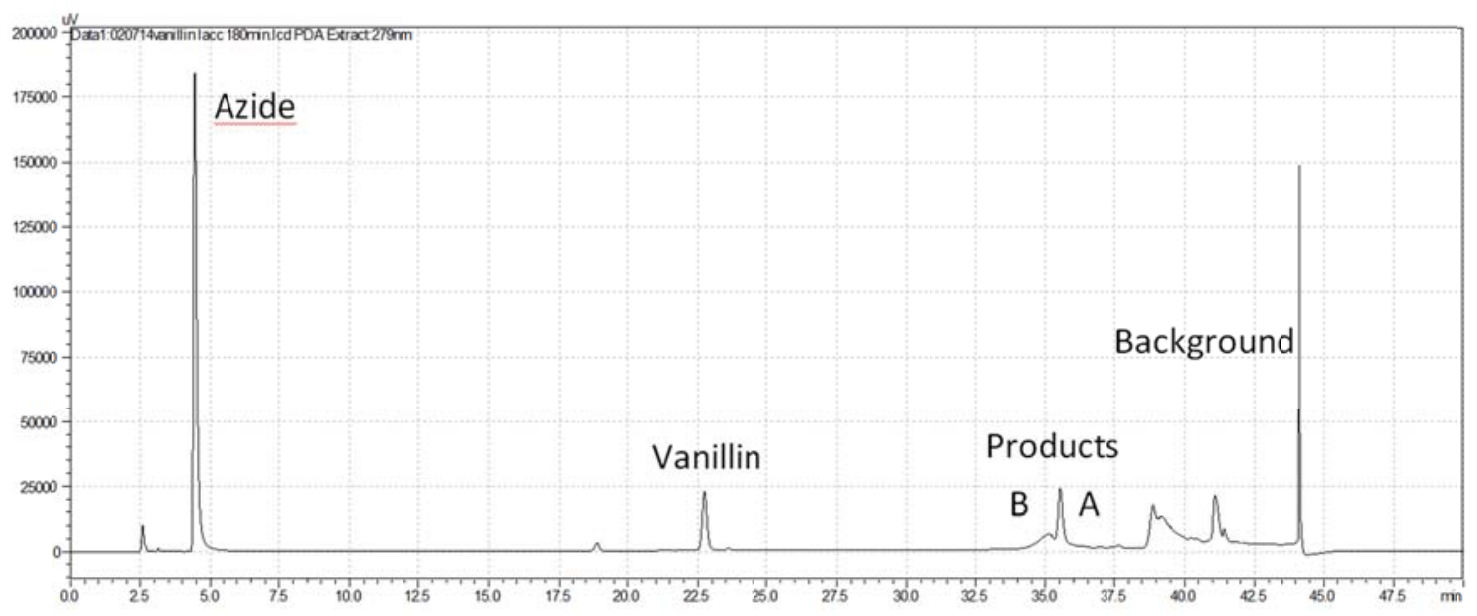

Figure 2. A typical HPLC chromatogram at $280 \mathrm{~nm}$ of the vanillin-laccase reaction from sample taken after 180 minutes with azide peak, vanillin peak and two product peaks B and $\mathrm{A}$. Other peaks are background.

This article is protected by copyright. All rights reserved. 


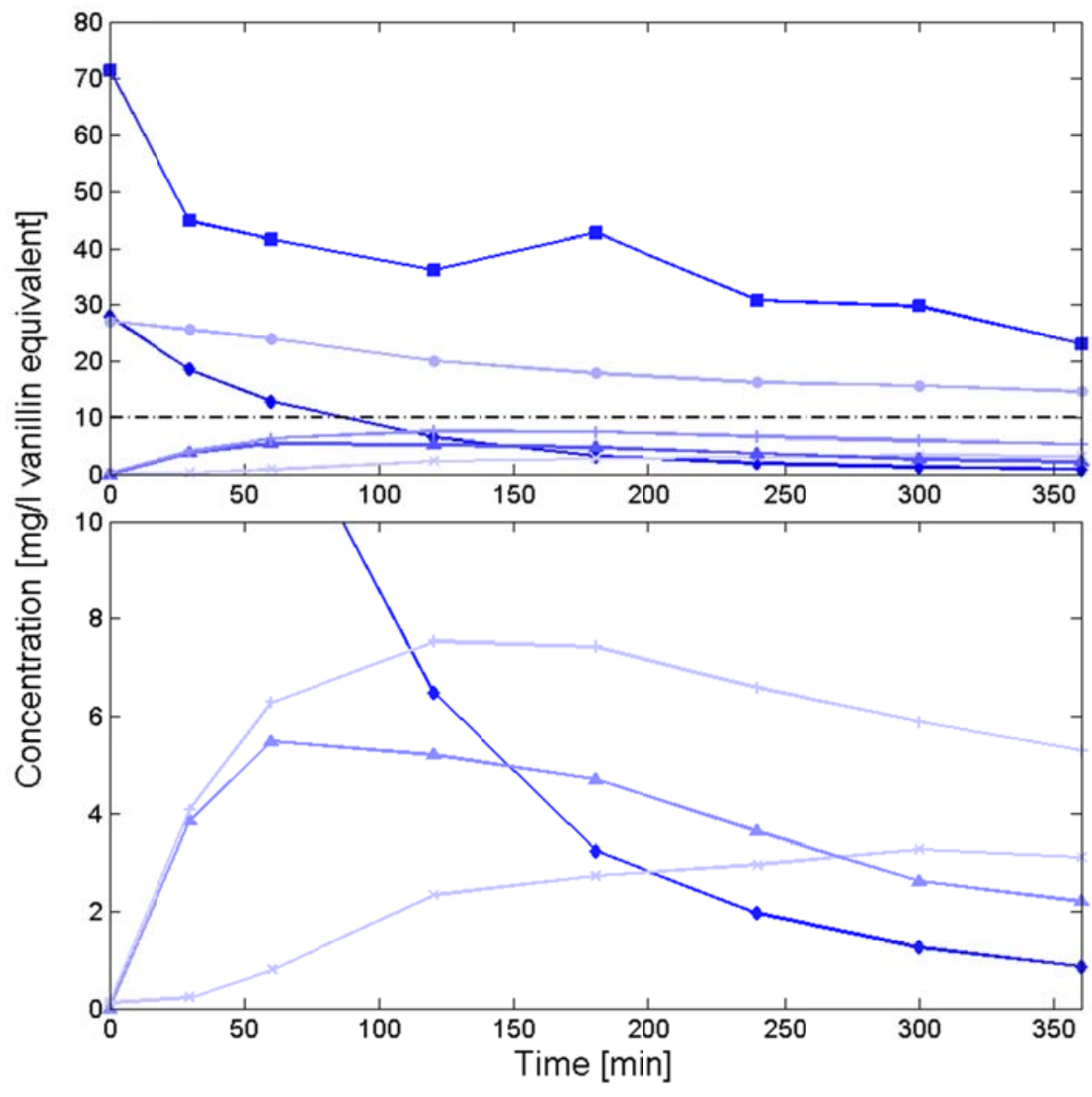

Figure 3. Concentration measurements of laccase vanillin reaction. The HPLC analysis of the reaction with $(\diamond)$ the vanillin concentration, $(x)$ product $A,(\Delta)$ product $B,(+)$ area of $A$ and B products together, ( $\square$ ) is the total area of all peaks obtained from the sample. The concentration calculated from the UV spectrometric absorbance at $280 \mathrm{~nm}$ are marked with $(\bullet)$. Figure A covers the whole range, while Figure B is a detailed view in the 0-10 $\mathrm{mg} / \mathrm{l}$ concentration range.

This article is protected by copyright. All rights reserved. 

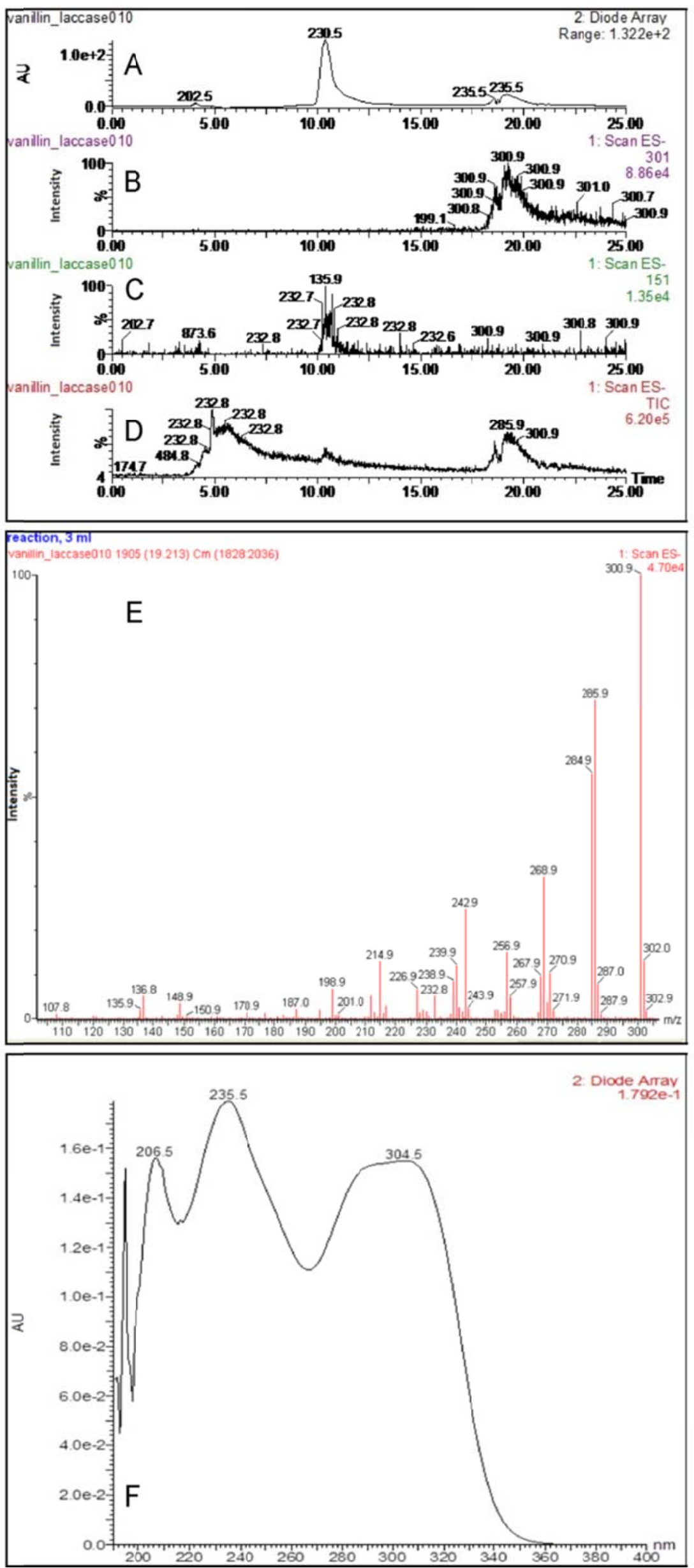
Figure 4. Preparative HPLC-MS chromatograms recorded during the purification of 3 ml sample. Graph A the general UV chromatogram, B the mass chromatogram at 301 $\mathrm{m} / \mathrm{z}, \mathrm{C}$ at $151 \mathrm{~m} / \mathrm{z}$, D the general mass chromatogram. Graph $\mathrm{E}$ is the mass spectrum taken from the product peak during fractionation and graph $F$ is the UV spectrum of the product peak.

This article is protected by copyright. All rights reserved. 


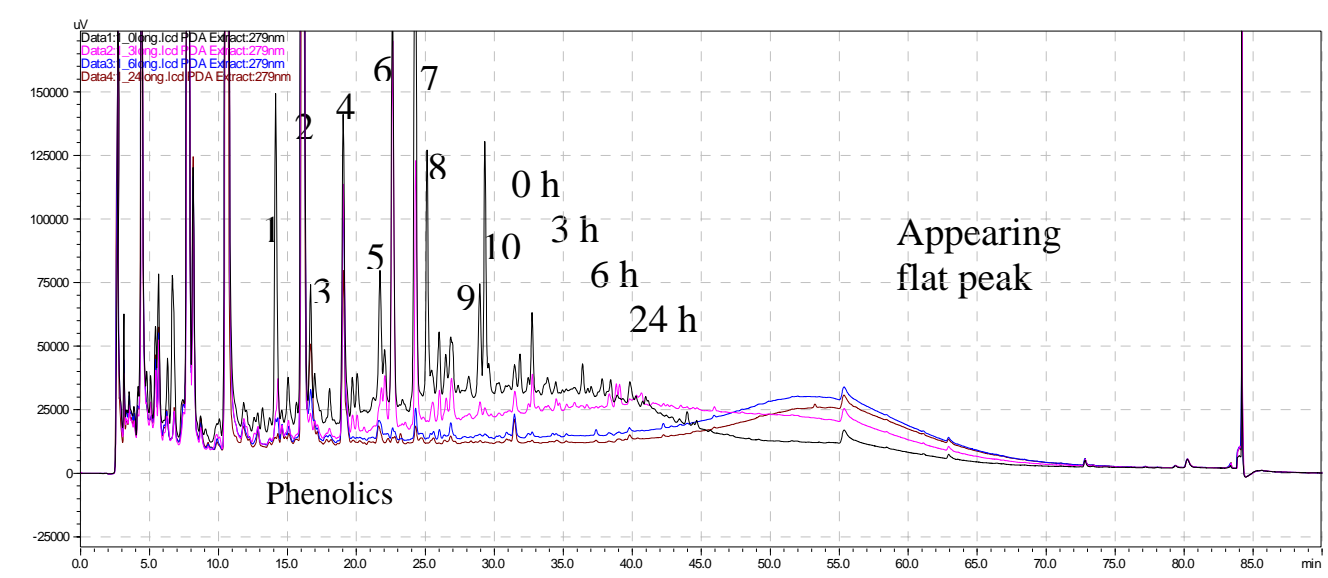

Figure 5. Measured HPLC chromatograms with Gradient $B$ after $0(-), 3(-), 6(-)$ and $24 \mathrm{~h}(-)$. The phenolics appear after the HMF peak at 12 minutes. Then main peaks were identified, numbered 1-9. The applied enzyme concentration was $2.95 \mathrm{U} / \mathrm{ml}$.

This article is protected by copyright. All rights reserved. 


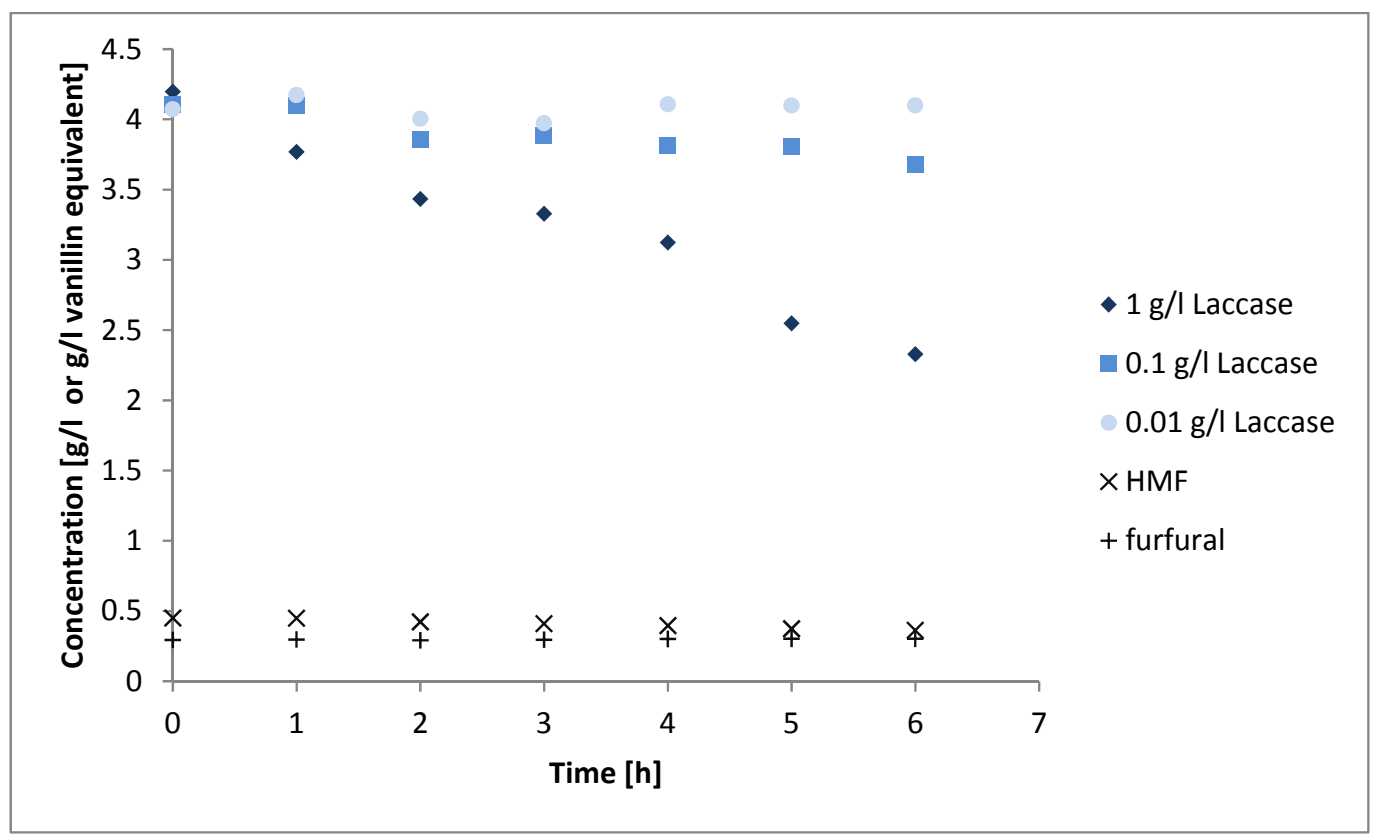

Figure 6. HPLC based concentration measurements of laccase XRF reaction. Phenolic concentrations are marked with $(\bullet) 0.03,(\square) 0.3$ and $(\diamond) 2.95 \mathrm{U} / \mathrm{ml}$ enzyme Concentration and are expressed in vanillin equivalent, (x) furfural and $(+)$ HMF are the averages for the three measurements.

This article is protected by copyright. All rights reserved. 


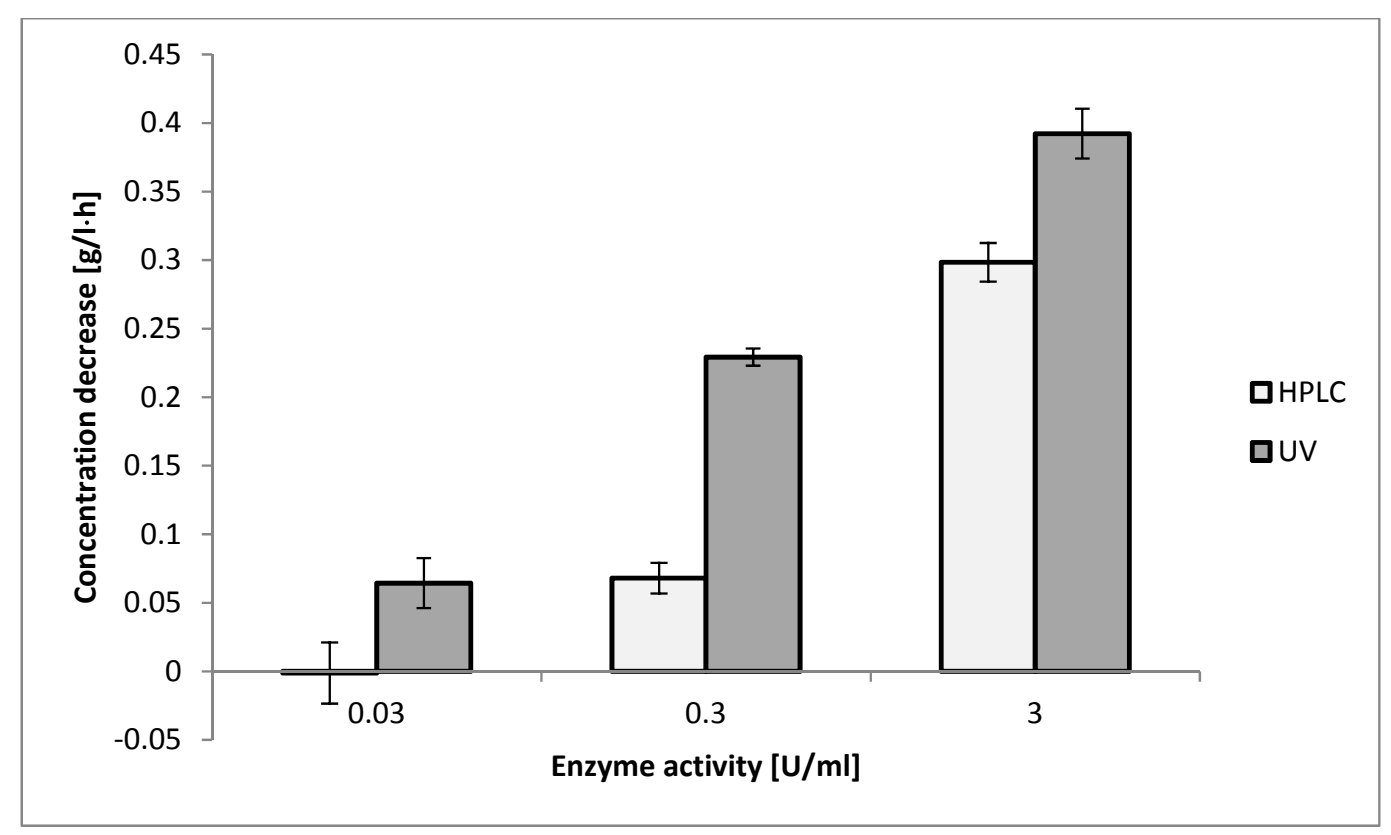

Figure 7. The slopes of decrease in phenolic concentration at three different enzyme concentrations and two different techniques: HPLC ( $\square$ ) and UV absorbance ( $\square)$.

This article is protected by copyright. All rights reserved. 